\title{
DiOTTOS
}

Revista de Comunicación Digital

\section{Oculto a simple vista: análisis de las comunicaciones diarias de la Conselleria de Sanidad durante la primera oleada del coronavirus}

\section{Hidden in plain sight: analysis of daily communications from the Department of Health during the first coronavirus wave}

\author{
Ximo Aguar Torres \\ Joaquin.Aguar@uv.es \\ Universitat de València
}

\author{
Guillermo López García \\ Guillermo.Lopez@uv.es \\ Universitat de València
}

\section{Resumen}

Este artículo analiza la comunicación de la Conselleria de Sanidad de la Comunitat Valenciana a lo largo de la primera ola de la pandemia del coronavirus SARS-CoV-2. Se trata de un período en el que la población española estuvo sometida a un riguroso confinamiento domiciliario para mitigar la propagación del virus, y donde el interés por adquirir información al respecto de la pandemia era máximo. En estas condiciones, la naturaleza de los mensajes emitidos diariamente desde la Conselleria de Sanidad, encargada de la gestión sanitaria de la pandemia en el territorio valenciano, resultaba del máximo interés informativo.

El objetivo de la investigación es determinar qué mensajes prevalecían en la estrategia de comunicación de la Conselleria mediante el análisis de un centenar de notas de prensa, difundidas a lo largo de los meses de febrero a junio de 2020. Es decir, a lo largo de la primera ola de la pandemia en España y de la desescalada que derivó en la "nueva normalidad" que dio fin al confinamiento en el mes de junio. Nuestra hipótesis de partida establece que la Conselleria de Sanidad intentaría minimizar los datos más negativos (contagios, hospitalizados, fallecidos) en su comunicación hacia la ciudadanía y los medios de comunicación, resaltando otros aspectos positivos (como los pacientes recuperados).

El análisis combina dos metodologías: un análisis de contenido cuantitativo, basado en palabras clave, de los titulares y subtítulos de las notas de prensa, para analizar los elementos que se buscaba destacar por parte de la Conselleria; y un análisis del discurso de las notas de prensa en su conjunto, que permita analizar el relato elaborado por la Conselleria a través del cual se aportaba la información. Dicho análisis permite validar nuestra hipótesis, pues muestra cómo tanto los titulares como las notas de prensa en su conjunto resaltaban casi sistemáticamente elementos positivos, mientras los datos adversos eran postergados en una posición subalterna en las noticias.

\section{Palabras clave}

coronavirus, covid, comunicación de crisis, comunicación institucional, notas de prensa, estrategias de comunicación, comunicación sanitaria

Edita: Miguel Vicente-Mariño

Recibido: 25/01/2021

Aceptado: 25/04/2021

Cómo citar este artículo:

Aguar Torres, X. y López García, G. (2021). Oculto a simple vista: análisis de las comunicaciones diarias de la Conselleria de Sanidad durante la primera oleada del coronavirus . Dígitos. Revista de Comunicación Digital, 


\begin{abstract}
This article analyzes the communication of the Conselleria de Sanidad de la Comunitat Valenciana during the first wave of the SARS-CoV-2 coronavirus pandemic. This was a period in which the Spanish population was subjected to rigorous home confinement to mitigate the spread of the virus, and where the interest in acquiring information about the pandemic was at its peak. Under these conditions, the nature of the messages issued daily from the Conselleria de Sanidad, in charge of the health management of the pandemic in the Valencian territory was of maximum informative interest.

The aim of the research is to determine which messages prevailed in the communication strategy of the Conselleria through the analysis of a hundred press releases, disseminated throughout the months of February to June 2020. That is, throughout the first wave of the pandemic in Spain and the de-escalation that led to the "new normality" that ended the confinement in June. Our starting hypothesis establishes that the Conselleria de Sanidad would try to minimize the most negative data (infections, hospitalized patients, deaths) in its communication to the public and the media, highlighting other positive aspects (such as recovered patients).

The analysis combines two methodologies: a quantitative content analysis, based on keywords, of the headlines and subheadings of the press releases, to analyze the elements that the Regional Ministry sought to highlight; and an analysis of the discourse of the press releases as a whole, which allows us to analyze the narrative developed by the Regional Ministry through which the information was provided. This analysis allows us to validate our hypothesis, as it shows how both the headlines and the press releases as a whole almost systematically highlighted positive elements, while the adverse data were postponed to a subordinate position in the news.
\end{abstract}

\title{
Keywords
}

coronavirus, covid, crisis communication, institutional communication, press releases, communication strategies, health communication oleada del coronavirus

\section{Introducción}

La pandemia provocada por el virus SARS-CoV-2, que en el momento de escribir estas líneas está aún lejos de remitir, cambió profundamente los hábitos de funcionamiento de nuestra sociedad. En pocos días, la población tuvo que asumir un confinamiento domiciliario extraordinariamente estricto, que duró meses, y que convirtió todo lo relacionado con la pandemia en el principal, y casi único, asunto de interés informativo. Los medios de comunicación informaron casi constantemente de la situación, y lo mismo hicieron las instituciones encargadas de gestionar el impacto de la pandemia en sus diversos planos (sanitario, laboral, económico, educativo, y un largo etcétera) ${ }^{1}$.

En lo que concierne específicamente a la Comunidad Valenciana, el primer caso de COVID-19 se hizo público el 25 de febrero de 2020. Valencia fue uno de los primeros

1. Este trabajo es producto de la participación de sus autores en el proyecto de I+D+i consolidable "Ecología de la desinformación: la construcción de las noticias falsas y su impacto en el espacio público" (AICO2020/224). Proyecto financiado por la Conselleria de Innovación, Universidades, Ciencia y Sociedad Digital de la Generalitat Valenciana (2020-2021). 
Gráfico 1: contagiados por COVID-19 en la Comunidad Valenciana, febrero 2020 - enero 2021. Fuente: Elaboración propia a partir de los datos del Ministerio de Sanidad

\section{Evolución de los contagios por covid-19 en la Comunitat Valenciana}

Por fecha de inicio de síntomas o de diagnóstico

Casos diarios Media móvil (7 días)

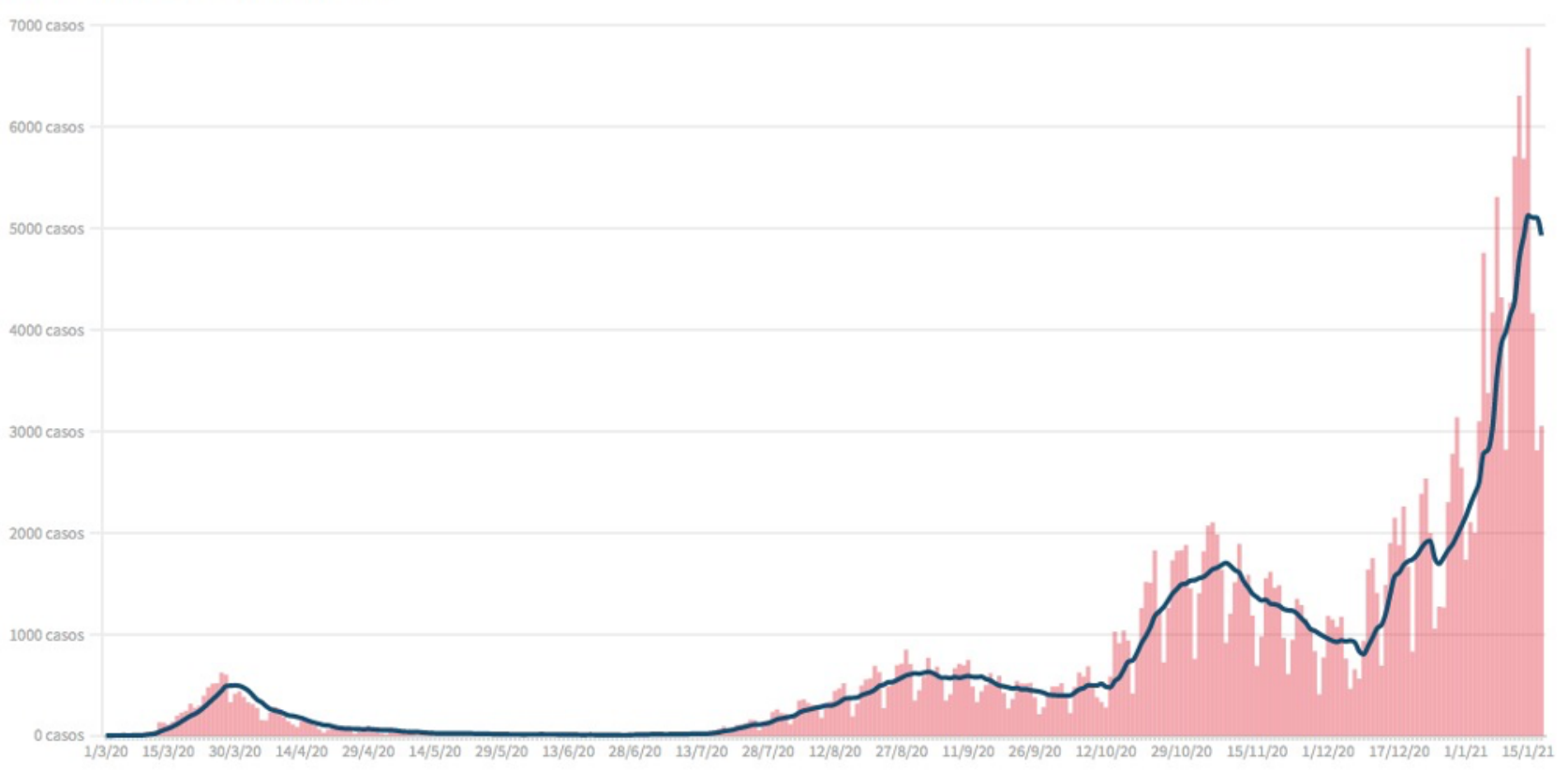

Gráfico 2: contagiados por COVID-19 en España, febrero 2020 - enero 2021. Fuente: Elaboración propia a partir de los datos del Ministerio de Sanidad

\section{Evolución de los contagios por covid-19 en España}

Por fecha de inicio de síntomas o de diagnóstico

- Contagios Media móvil (7 días)

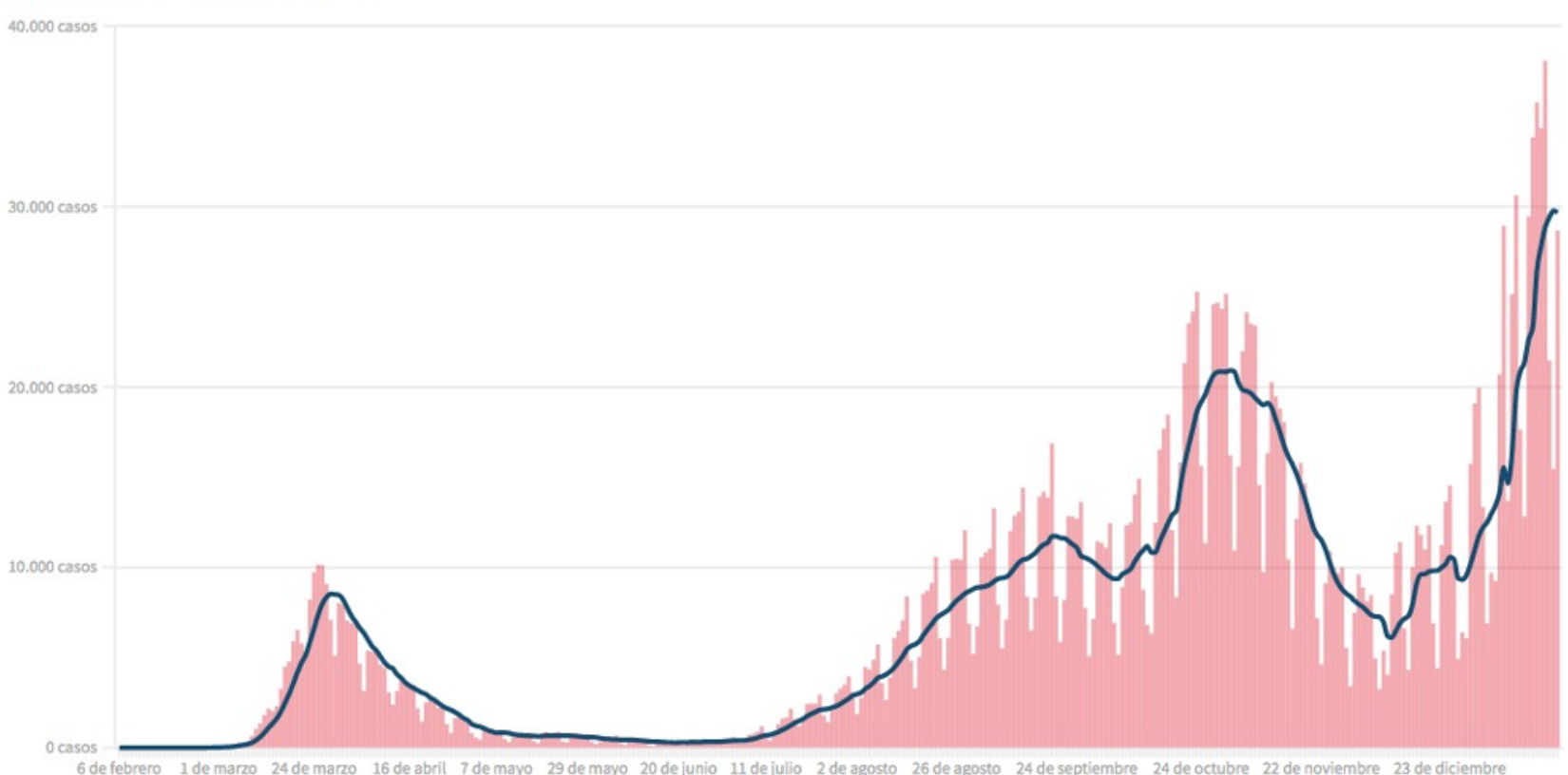


puntos de entrada de la pandemia en España, fundamentalmente desde Italia. La incidencia de la COVID-19 en la primera ola fue significativa, pero inferior al promedio del país, tanto en número de casos como de hospitalizaciones y fallecidos (en torno a la mitad de lo que le correspondería por población). En el Gráfico 1 puede verse la evolución de los contagios en la Comunitat Valenciana, más o menos el cinco por ciento del total en España en la primera y segunda olas, pero muy por encima del promedio en la tercera ola. En el Gráfico 2 puede observarse la evolución de los contagios en el conjunto de España.

En líneas generales, el balance que se hizo de la gestión de la crisis del coronavirus por parte de la Generalitat en la primera ola fue positivo, sobre todo por las mencionadas cifras y por otros indicadores, como la capacidad para hacer acopio de material sanitario que mostró el gobierno autonómico. Factores ambos en los que la Comunitat Valenciana destacó positivamente en relación con el conjunto de España.

\section{La comunicación de la pandemia desde la Conselleria de Sanidad de la Comunitat Valenciana}

Desde poco después de la aparición de los primeros casos en la Comunitat Valenciana (27 de febrero de 2020) y hasta el día 3 de julio, la Conselleria de Sanidad emitió diariamente al menos un comunicado de prensa con la actualización de datos respecto a la incidencia del coronavirus en la Comunitat Valenciana. Este comunicado de prensa resumía la información esencial sobre el estado de la cuestión relativa a la pandemia de COVID-19 en el territorio valenciano, y era habitualmente desglosado en comparecencias de la consellera de Sanidad, Ana Barceló.

En condiciones normales, los comunicados oficiales son una herramienta más para los periodistas, que habitualmente no se encuentran indefensos ante los posibles sesgos institucionales que puedan conllevar, puesto que cuentan con fuentes y mecanismos alternativos para acceder a la información. No obstante, en este caso revestían mucha importancia: se trataba de una crisis sanitaria donde la información estaba completamente centralizada, el volumen informativo era extraordinario y las propias plantillas, en muchos casos bajo un novedoso régimen de teletrabajo, disponían de menor capacidad y maniobrabilidad para contrastar las informaciones oficiales servidas en los comunicados. Además, se trataba, sin duda alguna, de un material de enorme interés informativo, que buena parte de la población seguía atentamente de manera diaria. Todo ello justifica, desde nuestro punto de vista, el interés de nuestro objeto de estudio, que se enmarca en la observación de la comunicación institucional en situaciones de crisis (Moreno, 2009), centrada en la difusión de información a los medios de comunicación.

Se trata, por tanto, de un modelo de comunicación institucional hasta cierto punto indirecto, porque no se dirige a la ciudadanía, sino a los medios de comunicación, como mediadores necesarios entre la institución y el público (Xifra, 2020), en un contexto de sobreexposición mediática e interés por adquirir información (Casero-Ripollés, 2020).

Las instituciones públicas responsables de la gestión de la crisis han vivido en este período una situación ambivalente: por un lado, se han multiplicado para ofrecer información y estar constantemente disponibles; por otro, han dado la sensación, a menudo, de que la información que ofrecían ocultaba o minimizaba datos esenciales (López-García, 2020). Además, la crisis comienza bruscamente, sin que se hubiera preparado previamente a 
la ciudadanía, y con la adopción de medidas (el estricto confinamiento domiciliario) sin parangón en nuestra democracia. Todo ello configura un escenario en el que el riesgo percibido es máximo, no sólo por la gravedad de la crisis, sino por la sensación de falta de control de las autoridades, que no habían preparado al público para dicha situación (Costa-Sánchez y López-García, 2020). Finalmente, la gestión y transmisión de los datos por parte de las instituciones ha sido, desde un primer momento, un aspecto polémico de la crisis, dadas las insuficiencias y errores en la recogida, tratamiento y puesta a disposición del público de los datos, sobre todo en los meses iniciales de la primera ola (Díez-Garrido y Renedo Farpón, 2020).

En este contexto, el objetivo de este estudio es analizar, partiendo de los comunicados oficiales de la primera oleada (desde el 27 de febrero hasta el 8 de junio), la manera de transmitir los datos diarios de la Conselleria de Sanidad, para calibrar los mensajes que se pretendían destacar, así como los que se trataban de minimizar o incluso obviar, analizando así si se incurrió en cierto grado de desinformación para favorecer la estrategia comunicativa del Ejecutivo. Nuestra hipótesis de partida plantea que los comunicados de prensa intentaron ofrecer una imagen de la pandemia y de la gestión del Gobierno valenciano nítidamente positiva, minimizando la información adversa y destacando los elementos favorables.

\section{Metodología}

El sistema empleado para este estudio se ha centrado en el análisis de los comunicados de prensa emitidos desde la Conselleria de Sanidad de la Generalitat Valenciana desde el 27 de febrero hasta el 4 de mayo de 2020, el inicio de la desescalada, aunque también se han consultado las notas emitidas posteriormente, hasta el 8 de junio, para observar la evolución de algunos de los ítems propuestos.

Para acotar los mensajes que la Conselleria de Sanidad quería destacar, hemos analizado el contenido de 100 notas de prensa, prestando mayor atención a los titulares, subtítulos o ideas destacadas en los comunicados. Además, hemos prestado especial atención a algunas palabras clave para constatar su utilización, y también nos hemos detenido en las construcciones utilizadas y sus variaciones ante el avance de la pandemia.

Así pues, para este estudio se ha utilizado un análisis de contenido cuantitativo, basado en la búsqueda y contabilización de determinadas palabras clave en titulares y subtítulos en 100 notas de prensa oficiales. Conceptos como positivos, fallecimientos, contagios, altas, profesionales sanitarios, ingresos y $\mathrm{UCl}$, son algunos sobre los que se ha realizado el seguimiento para determinar cuál ha sido las terminologías más y menos utilizadas desde la Conselleria de Sanidad en los encabezamientos de sus notas de prensa.

Además, también se ha desarrollado un análisis del discurso que mostrase la relación entre los datos y el contexto en el que se producían los diferentes comunicados, estableciendo relaciones entre la manera de elaborar las notas de prensa, las palabras priorizadas o inutilizadas y los datos que se enfatizaban en titulares y subtítulos, en el marco del escenario socio-político relacionado con la pandemia.

\section{Análisis}

El análisis se compone de una parte cuantitativa y otra cualitativa respecto a un centenar de comunicados de prensa oficiales remitidos por la Conselleria de Sanidad desde el 27 de febrero hasta el 8 de junio de 2020, aunque también se revisaron para este 
estudio otras notas publicadas, con el objetivo de corroborar los resultados principales del análisis.

En el ámbito cuantitativo, se ha analizado el número de veces que se han utilizado en los titulares y subtítulos de los comunicados algunas palabras -o sus derivados- que se consideran objetivamente relevantes en la comunicación de esta crisis sanitaria. Así, de los siete términos sujetos a revisión, el más utilizado en los titulares fue "altas" (hospitalarias), con 35 menciones en total (Tabla 1). De hecho, entre abril y mayo, pese a encontrarnos por momentos en la cresta de la primera ola de la pandemia, fue utilizada en 27 ocasiones, o lo que es lo mismo, prácticamente a diario.

La segunda palabra más usada en los titulares, con 26 menciones en total, fue "positivos", el concepto utilizado para referirse a los contagios diarios registrados. Su mayor vigencia se concentró en el primer mes de pandemia, dado que la Conselleria de Sanidad estableció una fórmula casi fija para los comunicados en la que se informaba de los nuevos casos usando este término. Posteriormente, la fórmula fue sustituida por "nuevos casos".

Elresto de palabras elegidas, como"fallecimientos", "contagios", "ingresos"(hospitalarios), "UCl" y "residencias", pese a la importancia informativa que conllevaban, no fueron apenas empleadas en los titulares en los dos primeros meses de crisis sanitaria. Posteriormente, como se aprecia en la horquilla entre mayo y junio, sí empezaron a cobrar cierta relevancia, pero siempre con un sentido positivo. Es decir, aprovechando la mejoría de las cifras, se empezaron a destacar determinadas cuestiones que hasta ese momento habían ocupado un segundo plano en las comunicaciones oficiales.

Tabla 1: Análisis cuantitativo de los titulares de las notas de prensa de la Conselleria de Sanidad, febrerojunio de 2020

\begin{tabular}{|l|c|c|c|}
\multicolumn{1}{c|}{} & \multicolumn{3}{c|}{ PALABRAS USADAS EN TITULARES POR FECHAS } \\
\hline TÉRMINOS & 27 FEB. - 31 MAR. & 1 ABR. - 4 MAYO & 5 MAYO - 8 JUN. \\
\hline Fallecimientos & 3 & 0 & 7 \\
\hline Positivos & 22 & 1 & 3 \\
\hline Contagios & 0 & 0 & 0 \\
\hline Altas & 1 & 27 & 7 \\
\hline Ingresos & 0 & 3 & 7 \\
\hline UCl & 0 & 3 & 9 \\
\hline Residencias & 1 & 0 & 2 \\
\hline
\end{tabular}

En los subtítulos analizados la estructura resulta similar (Tabla 2). La palabra "positivos" tuvo vigencia al inicio de la pandemia para convertirse en un término especialmente utilizado en los subtítulos entre abril y mayo, debido a que se desterró de los titulares y comenzó a usarse en la información destacada complementaria. Fue empleada 67 veces en esta parte del encabezado.

En segundo lugar, el concepto más usado fue "altas", que, tras protagonizar numerosos titulares entre abril y mayo, pasó a ocupar la mayor parte de los subtítulos entre mayo y junio, con 26 apariciones. En cuanto al resto de términos utilizados, se observa que tampoco fueron empleados en los subtítulos hasta que no empezaron a mejorar los 
datos de la pandemia entre mayo y junio.

Tabla 2: Análisis cuantitativo de los subtítulos de las notas de prensa de la Conselleria de Sanidad, febrero-junio de 2020

PALABRAS USADAS EN SUBTÍTULOS POR FECHAS

\begin{tabular}{|l|c|c|c|}
\hline TÉRMINOS & 27 FEB. - 31 MAR. & 1 ABR. - 4 MAYO & 5 MAYO -8 JUN. \\
\hline Fallecimientos & 1 & 0 & 4 \\
\hline Positivos & 17 & 37 & 13 \\
\hline Contagios & 2 & 0 & 2 \\
\hline Altas & 0 & 9 & 26 \\
\hline Ingresos & 0 & 3 & 7 \\
\hline UCI & 1 & 3 & 7 \\
\hline Residencias & 3 & 1 & 2 \\
\hline
\end{tabular}

En cuanto al análisis cualitativo, uno de los elementos más llamativos de la recogida de datos realizada es el uso de la palabra "fallecimientos" o sus derivadas en los encabezamientos (titular y subtítulos) de las notas de prensa. Si hablamos de una crisis sanitaria de este calibre, resulta obvio que el número de muertes diarias y totales es un hecho prioritario en el ámbito informativo. Sin embargo, sólo al inicio de la crisis, concretamente en los días 13, 15 y 16 de marzo, la Conselleria de Sanidad notificó en el titular que existían fallecimientos por coronavirus en la Comunitat Valenciana, pese a que no dejarían de producirse diariamente en mayor o menor medida hasta el 31 de mayo.

Un ejemplo de hasta qué punto la Generalitat trata de atenuar la alarma en la sociedad se produce en una de esas notas de prensa, concretamente la del 15 de marzo, donde sí se refleja un fallecimiento en el titular. La otra idea destacada, expresada en el subtítulo, rezaba lo siguiente: "La mujer fallecida tenía 75 años, su caso era importado, estaba ingresada en un hospital de Valencia y sufría una patología previa". Una síntesis que invita a la creencia de que el virus afectaba sólo a las personas mayores, con problemas de salud anteriores y que hubiera estado en contacto con personas de fuera de la Comunitat Valenciana. El día siguiente fue el último en el que se mencionaría la palabra "fallecimiento" en un titular o subtítulo hasta más allá de mes y medio después.

Es el 8 de mayo cuando la Conselleria recupera en sus comunicaciones oficiales este término, para notificar en el titular que no se ha producido ningún fallecimiento en residencias. De la misma manera, se utiliza posteriormente en subtítulos para recalcar que en alguna provincia, como Castellón, no se han producido fallecimientos.

El colofón a esta 'resurrección' de la palabra se produce el 31 de mayo, cuando la nota de prensa tiene como titular: 'La Comunitat Valenciana no registra ningún fallecido por coronavirus en las últimas 24 horas'. De hecho, hasta el 8 de junio, siete de las notas de prensa contuvieron dicha palabra, con un mensaje similar.

En esta línea, los fallecimientos tampoco ocuparon lugar en los subtítulos, ni tampoco en otros recursos destacados del comunicado. Generalmente, se situaban entre el cuarto y sexto párrafo de la información, aunque en alguna ocasión llegaron a reflejarse mucho más abajo.

Otro hecho relevante sobre esta cuestión es que nunca se ofrecía el número de 
fallecidos diarios en la nota, sino que se proporcionaba el dato acumulado, por lo que el periodista debía ir sumando manualmente la cifra. Un recurso que, a priori, podría parecer sencillo de desenmascarar, pero que ocasionó a menudo que, al menos en las versiones digitales de los medios de comunicación además de en los teletipos de las propias agencias, se pasara por alto la información concreta de la variación de un día a otro, lo que permitía a la Generalitat amortiguar en cierta medida el daño a su imagen de cosechar récords incluso consecutivos de fallecimientos diarios.

Esto dio cierto resultado en las primeras semanas de pandemia. La tensión sostenida en las redacciones, con teletrabajo, turnos y algunos ERTE, pudo contribuir a que el sesgo comunicativo en la información oficial difundida a diario surtiera cierto efecto para que algunos de los datos más negativos pudieran pasar más desapercibidos, sobre todo, en la información inmediata proporcionada por los nativos digitales y por las ediciones online de los grandes medios de comunicación.

Una circunstancia que, en los artículos más trabajados del día posterior, solía subsanarse tras analizar los datos con detenimiento. No obstante, la Conselleria de Sanidad evitaba así, al menos en ocasiones, el doble impacto negativo de tener en circulación un titular con un récord de fallecimientos a los pocos minutos de dar la información oficial y, al día siguiente, otro artículo ahondando en ese aspecto.

También resulta interesante analizar el paralelismo que se produce entre la palabra "fallecimiento" e "ingresos" hospitalarios -y sus derivados- durante las comunicaciones oficiales de la primera ola. Si las muertes son un elemento absolutamente clave para determinar la gravedad de la situación, no lo son menos los datos de pacientes que se encuentran en el hospital, ya sea en planta o en unidades de críticos, dado que constituyen el termómetro esencial para detectar el nivel de presión sanitaria y, con ello, un factor determinante para estimar, precisamente, una previsión de fallecimientos a corto plazo.

Así, la palabra "ingresos" y sus derivados fueron totalmente tabú en las comunicaciones oficiales durante casi los dos primeros meses de la pandemia, tanto en titulares como en subtítulos. Tal y como sucedió con los fallecimientos, este concepto solo aparece cuando puede ofrecerse un dato positivo en relación a la situación de la pandemia. Es el 25 de abril cuando sí se incluye en un subtítulo para hablar de la reducción de los ingresos en la $\mathrm{UCl}$. A partir de ahí, la Conselleria de Sanidad redobla su uso en esa misma línea positiva, incluyéndola en otro subtítulo el 27 de abril y, al día siguiente, con una declaración de la propia responsable autonómica, Ana Barceló: “Continúa el descenso en los ingresos por coronavirus en los hospitales y en las UCl de la Comunitat Valenciana".

Esta estrategia se prolonga durante varios días, con un titular el día 30 en el que se incide en el bajo porcentaje de pacientes que requieren ingreso en la $\mathrm{UCl}$ y otro el 2 de mayo recopilando información sobre la bajada de ingresos hospitalarios y en las $\mathrm{UCl}$. Una circunstancia que se repite en tono similar dos días después. A partir de esta fecha, estos términos - "ingresos" y "UCl"- se convierten, siempre en un sentido positivo, en un estilete para la Generalitat, que los utiliza hasta el 8 de junio en 16 ocasiones en los titulares y en 14 en los subtítulos.

Por otro lado, el patrón más constante de nota de prensa en esta primera oleada fue el de utilizar el titular para mencionar los nuevos positivos diarios. Bien es cierto que, en 
el peor momento de la pandemia -2 de abril, con récord de ingresados en los hospitales (2.189)-, se pasa a dar relevancia en el titular a las altas. Una manera de cambiar el paso para, probablemente, dar sensación de recuperación. Desde ese momento y hasta el 28 de abril, este concepto siempre ocupó un espacio en los titulares.

Es en esa fecha cuando la Conselleria de Sanidad vuelve a cambiar de tercio, para comenzar a titular las notas de prensa con recomendaciones o declaraciones optimistas de la responsable autonómica, Ana Barceló, en lo que parece un deseo de dar por superada la pandemia. Desde ese momento, los nuevos contagios desaparecen de los titulares -aunque seguían produciéndose- y se da paso a otro tipo de mensajes, como la reducción de ingresos hospitalarios o de UCl, o los "casos activos" -que no habían ocupado titular alguno desde el inicio de la crisis-.

Indiscutiblemente, uno de los focos de atención desde el inicio de la pandemia se situó en las residencias de mayores. En noviembre de 2020, se contabilizaban en la Comunitat Valenciana 700 ancianos fallecidos por coronavirus en estos centros $y$, también en esas fechas, se constataba que el $33,6 \%$ de los muertos de esta pandemia eran usuarios de los mismos.

Sin embargo, en muy pocas ocasiones las comunicaciones oficiales pusieron el acento en esta tragedia, sino que la información siempre fue incluida en el interior del texto; aunque, eso sí, generalmente bajo un ladillo (pequeño encabezamiento). En el primer mes de pandemia, solo en una ocasión apareció la palabra "residencia" -o derivadosen el titular de una nota de prensa. Fue el 18 de marzo: "La Conselleria de Sanidad informa que las pruebas realizadas a tres posibles casos de la residencia de Elche han resultado negativas". De nuevo una información que podía resultar positiva -ningún caso detectado-y con un subtítulo en el que se anunciaba la intervención de los posibles centros afectados por la Conselleria.

Previamente, la otra mención del término fue en un subtítulo el 12 de marzo que acompañaba al siguiente encabezamiento: 'Sanidad Universal confirma 24 nuevos casos positivos en la Comunitat Valenciana'. Subtítulo: 'Catorce de estos casos se han detectado en la residencia de mayores, lo que eleva a 30 la cifra de contagios en el centro'. Una información complementaria que indicaba que la mayoría de nuevos casos totales detectados se debían al brote en una residencia, lo que una vez más alimentaba la idea de focos localizados, puntuales y, por tanto, controlados.

Más allá de otra referencia puntual el 22 de marzo, el término "residencias" saldría de los encabezamientos de los comunicados oficiales de la Conselleria de Sanidad hasta finales del mes siguiente, pese a que se produjeron situaciones más que llamativas como que hasta 103 centros (casi un tercio del total) tuvieran al menos un positivo ( 2 de abril). Una vez más, el mensaje difundido cuando se retomó el término -en este caso en un subtítulo-, tenía connotaciones positivas: 'El $43 \%$ de las residencias que ha presentado algún caso positivo ya no tiene ninguno' (29 de abril). Por último, y continuando la tendencia de otras palabras clave analizadas, las "residencias" aparecían en el titular ya mencionado del 8 de mayo, cuando la primera ola remitía: 'La Comunitat Valenciana no registra ningún fallecimiento por coronavirus en residencias de mayores en las últimas 24 horas'.

Otro punto de interés es el trato que se le dio al apartado de profesionales sanitarios contagiados. Un hecho que mediáticamente fue muy destacado -especialmente por 
la falta de material- y del que la Conselleria empezó a informar -nunca en un lugar destacado del comunicado- a partir del 27 de marzo, cuando ya había 622 sanitarios contagiados. Sin embargo, el 22 de abril se deja de ofrecer ese dato en los comunicados oficiales, cuando el total de profesionales que había dado positivo era de 1.692 y existían 630 casos activos.

En todo el proceso, tampoco se dio cifra diaria de nuevos positivos entre los profesionales sanitarios, lo que obligaba a la suma manual. El hecho de dejar de dar información sin previo aviso, como en este caso, o realizar cambios en el conteo, como ocurrió en varias ocasiones con los test realizados, dificultaba enormemente la posibilidad de realizar recogidas de datos continuas y series gráficas.

Por último, otro dato interesante es la alteración de la fórmula habitual para presentar las cifras. Esto ocurrió, por ejemplo, a principios de abril, en el punto álgido de la pandemia y cuando el balance era especialmente negativo. Desde el 17 de marzo se venía proporcionando en el titular el número de "nuevos casos" o "nuevos positivos" registrados, pero el 2 de abril se apuesta por titular con las altas hospitalarias: 'Sanidad confirma 432 altas a pacientes con coronavirus en la Comunitat Valenciana, 192 más que el miércoles'. Curiosamente, se da la circunstancia de que ese día y el anterior se habían marcado los dos récords de hospitalizaciones en los centros sanitarios valencianos, con más de 2.000 personas ingresadas. También el 2 de abril se notificaban 48 nuevos fallecimientos, segundo peor dato de la pandemia, además de superar con creces el millar de sanitarios contagiados, 1.048. Todos ellos, datos que aparecen dentro del texto en párrafos no superiores, mientras que desde la Administración se apostó por destacar, por primera vez, el número de 'curados'.

Al día siguiente, el 3 de abril, se continúa dando prioridad en el titular a las altas a pacientes, mientras que, atendiendo al quinto párrafo del comunicado y realizando la resta correspondiente, se advierte que la Comunitat Valenciana marca el récord de fallecidos por la pandemia, con 68 muertes. El 4 de abril, se sigue el mismo patrón en el encabezamiento de la nota, mientras se registran 60 nuevos fallecidos -otra cifra muy alta-. El 5 de abril, se vuelve a incluir en el titular el número de contagios, pero se mantienen las altas hospitalarias, un formato que se mantendría intacto hasta el 27 de abril.

No obstante, en esa fecha se cambió de nuevo la fórmula del comunicado, para arrinconar también los nuevos casos positivos e iniciar una serie de notas de prensa con sabor a recuperación, que empezaron con dos días consecutivos de declaraciones de la consellera proclamando el descenso de los ingresos hospitalarios y solicitando el apoyo de la ciudadanía. A partir de ese momento, las comunicaciones oficiales, como ya se ha mencionado anteriormente, empiezan a dar cabida a los términos hasta ahora 'ocultados' para proclamar el descenso de cifras negativas.

\section{Conclusiones}

La principal conclusión de este análisis es la existencia de un cierto sesgo informativo en las comunicaciones oficiales de la Conselleria de Sanidad durante la primera ola de la pandemia de COVID-19. Las fórmulas utilizadas para las notas de prensa se basaron en la intención de lanzar mensajes dirigidos en cada momento para amortiguar o soslayar datos negativos y enfatizar cifras o situaciones positivas según los intereses 
de la Generalitat. Esto se evidencia en que no se aplicó una mera actualización de datos diaria aséptica -separada de una valoración política-, ni se apostó por una fórmula única e invariable para las comunicaciones oficiales. La forma de presentar y transmitir los datos fue modificándose durante la pandemia e incluso ajustándose al mensaje político que pretendía trasladarse.

Así, las notas de prensa con las que la Conselleria de Sanidad informaba sobre la evolución de la crisis atravesaron distintas fases durante la primera ola: tras unos inicios en los que se coqueteó con la negación de la realidad o, cuanto menos, la edulcoración de la misma, se pasó a un estándar de notas de prensa -desde el 17 de marzo al 2 de abril- en el que en el titular se daba importancia al número de nuevos casos del virus, hubiera o no datos más importantes, como número de fallecidos, crisis en las residencias, o récord de hospitalizados.

Este es un aspecto muy relevante, dado que el número de contagios confirmados no podía dispararse en exceso en aquellos momentos, debido a que el número de test era muy limitado al principio de la pandemia por una cuestión de existencias. Es decir, la Conselleria de Sanidad, en el peor momento de la primera ola, eligió una fórmula para titular los comunicados oficiales que hacía referencia a una cifra que era relevante -número de nuevos casos-, pero que difícilmente podía resultar escandalosa de forma sorpresiva, debido al conocimiento de la capacidad de pruebas PCR que se podía realizar diariamente.

De hecho, tal y como se ha comprobado en la segunda ola, los números de positivos diarios que se cuantificaban durante el inicio de la pandemia eran mucho menores que los que se dan en la actualidad. Como muestra, el 29 de marzo se alcanzó -en esa etapa- el récord de contagios notificados en un día con 750, mientras que a principios de 2021, concretamente el 20 de enero, se registraba la cifra más alta de positivos en 24 horas, con 9.810 nuevos casos. Pese a este elevadísimo número de contagios diarios, los ingresos hospitalarios de marzo eran superiores -tanto en planta como en las UCl- a los de diciembre, en el inicio de la tercera ola, y sólo en enero, en un contexto en el que la Comunitat Valenciana llegó a encabezar las cifras de incidencia del virus en España, llegaron a superarse. Lo cual indica que, muy probablemente, el número de positivos en la primera ola era muchísimo más alto, pero el ritmo de pruebas -entre 1.000 y 2.000 diarias en aquel momento- era muy inferior a las 25.000 de media diaria que se realizaban en enero de 2021. Es decir, la opción por parte de la Conselleria de Sanidad, premeditada o no, de titular de forma continua con el número de nuevos casos facilitaba una sensación de estabilidad, dado que el dato, aunque pudiera ser negativo, se situaba dentro de unos parámetros hasta cierto punto controlados.

Más allá de esta cuestión, del análisis se desprende que la Generalitat Valenciana trataba de fijar con sus comunicaciones oficiales un mensaje positivo, incluso en los peores momentos de la crisis, mediante dos estrategias: destacar las informaciones positivas (recuperados, curados, descenso o ausencia de la mortalidad), por un lado; y minimizar o arrinconar los negativos (fallecidos, hospitalizados, situación de las residencias o de los sanitarios contagiados). La estrategia comunicativa se basaba en "ocultar a simple vista" los datos que no se querían destacar, ubicándolos en posiciones subalternas en la información y desglosándolos de manera que fuera más complicado obtener una visión de conjunto. No puede decirse que se ocultasen cifras esenciales, pero sí que el 
discurso y la estructura de las notas de prensa pretendían ubicarlas en segundo plano si éstas eran negativas para los intereses de la Conselleria. Así, esta manera de actuar se aprecia de forma especial en los días en los que se produce algún dato negativo, tal y como este análisis ha mostrado que ocurrió en la recta final de marzo y principios de abril.

En este sentido, la fórmula de romper con la nota de prensa 'tipo' establecida para promocionar alguna circunstancia positiva y/o minimizar alguna negativa se ha prolongado en el tiempo. Durante el mes de diciembre de 2020, el patrón ha sido mencionar en el titular los "nuevos casos", y sólo se ha roto en tres ocasiones: una para 'celebrar' que 100.000 personas en la Comunitat Valenciana habían "superado la pandemia" (2 diciembre), otra para subrayar que más de un millón de valencianos se habían sometido a una PCR (17 diciembre) y la tercera, la más llamativa, para señalar que la Comunitat Valenciana registraba una incidencia acumulada de 363 contagios por cada 100.000 habitantes (29 de diciembre). Un dato que nunca se había utilizado para un titular y que coincidía con el récord absoluto de positivos de toda la pandemia en la Comunitat Valenciana (3.590), lo que pone de manifiesto el deseo, en este caso algo infantil, de querer pasar a segundo plano la cifra informativa más relevante.

En relación con esto, una de las claves para entender que, en estos casos, sí existía una táctica deliberada es, según se ha observado durante el análisis, cómo algunos de los indicadores más negativos de la pandemia (fallecimientos, hospitalizados o situación de las residencias de mayores) pasaban a primer plano cuando cabía la posibilidad de notificar alguna novedad positiva sobre los mismos. Era entonces cuando eran 'desenterrados' del fondo de las notas de prensa para darles protagonismo en titulares y subtítulos, e incluso facilitando o elaborando estadísticas que hasta ese momento no se habían proporcionado.

En resumen: frente a la situación de grave crisis sanitaria que asoló a la Comunitat Valenciana durante la primera ola de la pandemia de la COVID-19, la Conselleria de Sanidad ofreció las informaciones esenciales a los medios de comunicación. Pero en todo momento lo hizo aplicando una estrategia de comunicación institucional que buscaba resaltar los elementos positivos y emborronar la existencia de cifras adversas. La Conselleria aplicó criterios, si no propagandísticos, sí impropios de su papel como agencia pública que transmite una información relevante al público a través de los medios, aunque desgraciadamente común en la comunicación de los organismos oficiales en España, como se corresponde con nuestro modelo mediático de pluralismo polarizado (Hallin y Mancini, 2004). Y particularmente en lo que atañe a la gestión comunicativa de la crisis del coronavirus por parte del Gobierno español, que podría catalogarse como una estrategia de marketing cuya finalidad era "vender" el papel heroico del presidente del Gobierno (Añel y Rodríguez, 2020).

El sesgo de los mensajes elaborados desde la Conselleria de Sanidad constituye un asunto en absoluto menor, si tenemos en cuenta la enorme relevancia informativa y el interés público sobre este asunto, así como la naturaleza de las cuestiones sobre las que se informaba en dichas notas de prensa, que casi invariablemente incluían fallecidos por la enfermedad. A pesar de lo cual, la Conselleria de Sanidad sólo consideraba oportuno destacar dicha circunstancia precisamente cuando ésta no concurría, es decir: cuando no había fallecidos. Los muertos, en cambio, no eran noticia, y había que rebuscarlos 
en el interior de las notas de prensa de la Conselleria.

\section{REFERENCIAS}

Añel Rodríguez, R. M. y Rodríguez Bilbao, E. (2020). “La comunicación en la crisis del Covid-19:relatoúnico, marco épicoyrelatosausentes". Revista Españolade Comunicación en Salud, Suplemento 1. 293-393. https://doi.org/10.20318/recs.2020.5423

Casero-Ripollés, A. (2020). "Impact of Covid-19 on the media system. Communicative and democratic consequences of news consumption during the outbreak". El profesional de la información, v. 29, n. 2, e290223. https://doi.org/10.3145/epi.2020.mar.23

Costa-Sánchez, C.; López-García, X. (2020). “Comunicación y crisis del coronavirus en España. Primeras lecciones". El profesional de la información, v. 29, n. 3, e290304. https://doi.org/10.3145/epi.2020.may.04

Díez-Garrido, M. y Renedo Farpón, C. (2020). "La transparencia institucional y mediática del coronavirus. Un análisis de los portales de datos y de los medios de comunicación digitales en Iberoamérica". Revista Latina de Comunicación Social, 78, 393-418. https:// doi.org/10.4185/RLCS-2020-1482

Hallin, D., y Mancini, P. (2004). Comparing Media Systems: Three Models of Media and Politics. New York: Cambridge University Press.

López-García, Guillermo (2020). “Vigilar y castigar: el papel de militares, policías y guardias civiles en la comunicación de la crisis del Covid-19 en España". El profesional de la información, v. 29, n. 3. pp. 1-15. https://doi.org/10.3145/epi.2020.may.11

Moreno-Castro, C. (Ed.) (2009). Comunicar los riesgos. Ciencia y tecnología en la sociedad de la información. Madrid: Biblioteca Nueva. ISBN: 978-8497429269

Xifra, J. (2020). "Comunicación corporativa, relaciones públicas y gestión del riesgo reputacional en tiempos del Covid-19". El profesional de la información, v. 29, n. 2, e290220. https://doi.org/10.3145/epi.2020.mar.20 